\title{
Carved from oxygenates
}

Sci. Adv. 5, eaav3680 (2019)

Bimetallic complex precursor

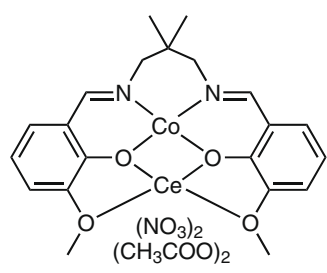

Test reaction<smiles>CC(=O)c1ccccc1</smiles>

Acetophenone

$$
\begin{gathered}
\underset{\text { Co-Ce/C catalyst }}{\stackrel{4 \mathrm{MPa} \mathrm{H}}{2}} \\
\underset{\text { methylcyclohexane }}{110^{\circ}}
\end{gathered}
$$

$110^{\circ} \mathrm{C}, 20 \mathrm{~h}$<smiles>CCc1ccccc1</smiles>

Ethylbenzene $(98 \%)$

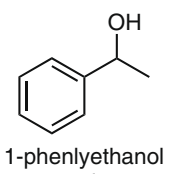

n.d.

Selected examples from substrate scope analysis<smiles>Fc1ccc(CCc2ccccc2)cc1</smiles>

$81 \%$<smiles>CCc1ccc(I)cc1</smiles>

$71 \%$<smiles>Cc1ccc(B2OC(C)(C)C(C)(C)O2)cc1</smiles>

$78 \%$<smiles>OCCCCc1ccccc1</smiles>

From carbonyl-based substrate
Methods to deoxygenate organic molecules are very important to customize the pattern of substituents in synthetic targets such as fine chemicals or building blocks for synthesis. However, deoxygenation methods are almost exclusively based on platinum group metals and are dominated by homogeneous approaches. Now, Rhett Kempe and colleagues introduce an earth-abundant bimetallic heterogeneous catalyst competent for the chemoselective deoxygenation of a diverse family of organic compounds with high efficiency.

The catalytic system is prepared by impregnation of activated charcoal with a heterobimetallic Schiff base complex of cobalt and cerium (pictured), followed by pyrolysis. The resulting Co-Ce/C composite features small Co nanoparticles with a mean size of $6.8 \mathrm{~nm}$ surrounded by small Ce clusters (around $1 \mathrm{~nm}$ ) highly dispersed in the carbon matrix. The authors benchmarked the activity of the system using the hydrodeoxygenation of acetophenone in the presence of hydrogen as a test reaction. Based on control experiments with monometallic Co or Ce catalysts, the simultaneous presence of both metals is crucial to achieve the selective formation of ethylbenzene over 1-phenylethanol. Similarly, employing supports other than charcoal for the preparation of the bimetallic system - that is, $\mathrm{TiO}_{2}, \mathrm{CeO}_{2}$, or $\gamma-\mathrm{Al}_{2} \mathrm{O}_{3}$ - has negative effects on both yield and selectivity. The mechanistic investigation also revealed that the synergy between metallic $\mathrm{Co}$ and mixed $\mathrm{Ce}^{3+} / \mathrm{Ce}^{4+}$ species at the surface of the catalyst is essential to trigger the desired hydrodeoxygenation reactivity.

$\mathrm{Co}-\mathrm{Ce} / \mathrm{C}$ turns out to be a very versatile catalyst when it comes to substrate scope. The system can deoxygenate a variety of aryl-alkyl ketones but also their related secondary alcohols. Furthermore, the corresponding aldehydes and primary alcohols can also be effectively transformed, albeit slightly harsher reaction conditions are required. A remarkable aspect of the method is the tolerance towards halogen substituents, which are usually cleaved by other catalysts under similar hydrogenation conditions. The only drawback in the case of halogenated species is the need of acid additives required to activate the substrate. The team further expanded the scope of the method by including selected examples of aliphatic alcohols as well as diols or bioactive molecules like ketoprofen.

\section{Davide Esposito}

Published online: 12 December 2019 https://doi.org/10.1038/s41929-019-0413-5 